\title{
INTELIGIBILIDAD EN POTENCIA, POTENCIALIDAD INTELECTUAL E INTELIGIBILIDAD INTRÍNSECA: TRES NIVELES ANALÓGICOS DE PERFECCIÓN EN TOMÁS DE AQUINO
}

\author{
MARÍA DEL ROSARIO NEUMAN \\ Universidad San Damaso (Madrid)
}

\begin{abstract}
RESUMEN: Una de las denominaciones utilizadas por santo Tomás para referirse al ente corpóreo y al espiritual es la de «inteligible en potencia» e «inteligible en acto». En el presente artículo se profundiza en el significado y alcance de estos conceptos, y en los fundamentos ontológicos de tal distinción. Se considera al alma en cuanto que ocupa el último lugar en el género de lo inteligible, y desde ahí se da razón de la distinción sujeto-objeto que tiene lugar en el acto de conocer humano. A partir de la noción de inteligible en acto, se argumenta a favor de la superación de esta distinción en el acto de conocimiento de sí que tiene una forma separada. Finalmente, y siguiendo en esta cuestión a Francisco Canals, se da razón de la preeminencia que en el pensamiento del Aquinate tiene la intimidad y subsistencia en sí del espíritu por sobre cualquier pasividad o receptividad.
\end{abstract}

PALABRAS CLAVE: conocimiento, inteligible en potencia, inteligible en acto, sujeto, objeto, entendimiento agente, conocimiento del alma.

\section{Intelligibility in potency, intellectual potentiality and intrinsic intelligibility: Three analogical levels of perfection in Thomas Aquinas}

ABSTRACT: One of the notions used by Saint Tomas Aquinas to refer to the corporeal being and to the spiritual being is that of «intelligible in potency» and «intelligible in act». This article delves into the meaning and scope of these concepts and in the ontological foundations of the previous distinction. The soul is considered as occupying the last place among the intelligible beings and this explains the distinction subject-object with occurs in the act of human knowledge. When considering the notion of intelligible in act an argument is found in favour of that distinction being overcome in the act of self-knowledge of a separate form. Finally, following Francisco Canals in this point, the article shows the preeminence, in the Aquinas' thoughts, of the intimacy and subsistence of the spirit above any passivity or receptivity.

KEY WORDS: knowledge, intelligible in potency, intelligible in act, subject, object, agent intellect, souls's self-knowledge.

\section{INTRODUCCIÓN}

En un artículo que lleva por título «Verdad trascendental y subsistencia espiritual en Santo Tomás», Francisco Canals hace la siguiente afirmación: «el entendimiento humano y lo entendido no difieren entre sí a modo de sujeto y objeto sino en razón de la potencialidad del sujeto en su naturaleza intelectual y del carácter "extrínseco" al orden de lo inteligible propio de las cosas "extra 
intellectum" " ${ }^{1}$. La tesis central del artículo es que, para santo Tomás, la oposición sujeto-objeto no es constitutiva del conocimiento en cuanto tal. En el presente trabajo desarrollaremos los dos presupuestos contenidos en la afirmación de Canals: 1) la potencialidad del sujeto humano en su naturaleza intelectual; 2) el carácter «extrínseco» al orden de lo inteligible propio de las cosas «extra intellectum». En orden a profundizar en estas cuestiones, se analizará paralelamente 1) la inteligibilidad intrínseca, y 2) la actualidad intelectual de una forma separada.

La distinción entre inteligible en acto e inteligible en potencia es central en el pensamiento del Aquinate. Nos parece, no obstante, que no ha sido una cuestión suficientemente atendida por los estudiosos de santo Tomás contemporáneos. Su consideración es provechosa por cuanto permite ahondar tanto en la potencialidad, como en la actualidad del entendimiento humano. En este trabajo recogemos y profundizamos en las consideraciones que sobre esta cuestión han realizado dos de los representantes más destacados de la llamada «Escuela tomista de Barcelona», Jaume Bofill y Francisco Canals.

\section{INTELIGIBLE EN POTENCIA: DISTINCIÓN ENTRE ESSE NATURAL Y ESSE INTELIGIBLE}

Es central en la filosofía de santo Tomás la consideración de que el objeto proporcional al entendimiento humano, el ente corpóreo, sólo es inteligible en potencia. El Aquinate lo afirma claramente: «lo inteligible en acto no es algo que exista en el orden de las realidades naturales sensibles, que no subsisten sin la materia $»^{2}$. A partir de esta observación, aunque no es el objeto de este artículo, se podría justificar toda la estructura cognoscitiva del hombre, desde la necesidad de facultades sensibles hasta la de un entendimiento agente y otro potencial. Para santo Tomás, propiamente, inteligible en acto es el subsistente inmaterial. Ahora bien, también es inteligible en acto aquello que está siendo actualmente considerado por el entendimiento humano.

Una realidad que es inteligible en potencia, un ente corpóreo, existirá como inteligible en acto al constituirse en objeto de entendimiento de una inteligencia. En palabras del Aquinate: las cosas materiales «no son inteligibles más que porque nosotros las hacemos inteligibles $»^{3}$. Ahora bien, esta afirmación debe ser correctamente entendida. En efecto, se podría pensar que aquello que pasa de «ser inteligible en potencia» a ser «inteligible en acto» es el mismo ente en su ser natural. Como es evidente, tal suposición encierra en sí un absurdo: la cosa corpórea habría de duplicarse para existir en el entendimiento. En cuanto

1 CANALS, F., «Verdad trascendental y subsistencia espiritual en Santo Tomás» en Cuestiones de Fundamentación, Publicacions i Edicions Universitat de Barcelona, Barcelona, 1981, p. 188. Este artículo salió publicado por primer vez en Convivum, 1975 (46).

2 Tomás de Aouino, Summa Theologiae, I, q. 79, a. 3, ad 3.

3 Tomás de Aquino, De Veritate, q. 2, a. 2 
que duplicada, ya no sería la misma. No hay propiamente paso de existir en potencia a existir en acto, porque no hay una «materia» que haga de sujeto de tal cambio. La existencia de una materia tal haría inviable el conocimiento: lo inteligible en acto supondría la corrupción de lo inteligible en potencia. Como es sabido, lo inteligible en acto no se diferencia de lo inteligible en potencia, sino como lo abstracto de lo concreto: lo entendido en acto es la forma del subsistente (inteligible en potencia) que ha sido abstraída del compuesto. La inteligibilidad en potencia, tal como ha sido caracterizada, designa formalmente la imposibilidad del subsistente corpóreo de «existir como presente en el espíritu o actuar sobre el mismo» ${ }^{4}$.

La razón por la cual el singular material no puede ser objeto directo de intelección es precisamente su corporeidad. Así lo precisa el Aquinate: «el singular es ininteligible no en cuanto singular, sino por ser material, ya que nada es entendido sino inmaterialmente ${ }^{5}$. No todo singular es inteligible sólo en potencia. En la escala de los entes, las llamadas formas separadas o ángeles, según precisa santo Tomás, son inteligibles en acto. Un inteligible en acto es una realidad que, puesto que su propia esencia es el principio inmediato de su intelección, existe para sí como inteligente e inteligible. Santo Tomás desarrolló exhaustivamente el modo de ser de estas substancias. Uno de los pasajes centrales en relación a esta cuestión es Summa Theologiae, I, q. 56, a. 1: "por lo demás para que la forma sea principio de acción, lo mismo da que sea inherente o subsistente por sí (...). Así, pues, si en el orden de lo inteligible existe algo que sea forma inteligible subsistente, se entenderá en sí mismo» ${ }^{6}$. El ángel es forma inteligible subsistente, luego «se entiende a sí mismo por su forma, que es su sustancia» ${ }^{7}$.

Puesto que más adelante profundizaremos en esta cuestión, baste por el momento limitarnos a destacar que la inteligibilidad intrínseca del ente lleva consigo identidad entre el esse natural y el esse inteligible. Señala al respecto santo Tomás: «en cada ángel fue impresa la razón de su especie según el ser natural y a la vez según el ser inteligible, de modo que subsistiese en la naturaleza de su especie y por ella se entendiese a sí mismo» ${ }^{8}$. Esto es, una misma razón formal

4 Canals, F., Sobre la esencia del conocimiento, PPU, Barcelona, 1987, p. 115. Polo explica esta cuestión afirmando que «el acto de ser de la piedra no hace inteligible o cognoscible en acto a la piedra. Sólo con relación a un acto de conocer la piedra se puede decir conocida en acto»; Polo, L., Curso de Teoría de conocimiento I ( $2^{\text {a }}$ ed.), Eunsa, Pamplona, 1987, p. 115.

5 Tomás de Aouino, Summa Theologiae, I, q. 86, a. 1, ad 3.

6 Tomás de Aquino, Summa Theologiae, I, q. 56, a. 1. Cfr. In I Sententiarum, d. 35, q. 1, a. 1.

7 Tomás de Aouino, Summa Theologiae, I, q. 56, a. 1. Esta doctrina se encuentra presente tanto en Báñez como en Juan de Santo Tomás. Cfr. García del Muro, J., Ser y conocer, PPU, Barcelona, 1992, p. 279, n. 46.

8 Tomás de Aouino, Summa Theologiae, I, q. 56, a. 2. Tal como señaló Cayetano, «porque es el mismo en tal modo de ser natural lo que es en acto inteligible, ya que ese ser natural es inteligible en acto, por esto puede entenderse a sí mismo por sí mismo»; Cayetano, In Summa Theologiae, I, q. 56, a. 1. Canals sintetiza esta doctrina: «una sustancia inmaterial 
subsiste en ser natural y es entendida en acto. Esta doble tenencia del ser, en esse naturale y en esse inteligibile, es denominada por santo Tomás: «intuición intelectual de sí». "Las esencias de las cosas materiales están en el entendimiento del hombre y en el del ángel, no según su ser real, sino a la manera como lo entendido está en el que entiende, sin perjuicio de que haya cosas que tengan en el entendimiento del ángel y en el alma humana ambas maneras de ser, pues la visión intelectual se extiende a unas y otras» ${ }^{9}$. La presencia intencional de sí de una forma separada, por tanto, entraña a la vez presencia óntica ${ }^{10}$.

En el siguiente apartado presentaremos los fundamentos ónticos de la diferencia entre ser inteligible en potencia y ser inteligible en acto.

\section{Constitución ONTOLÓGICA DE UN INTELIGIBLE EN POTENCIA}

En virtud de la composición materia-forma, en el ente móvil el esse natural no es a la vez esse inteligible, o, la presencia óntica no entraña a la vez presencia intencional. Además de ser causa de la multiplicidad, la composición materiaforma introduce, como desarrollaremos, falta de identidad en el subsistente. En efecto, el ente corpóreo se encuentra desde su constitución traspasado por dos principios: el principio determinante y el principio determinado. Como es sabido, el principio determinante, la forma sustancial, es aquello por lo que el ente se sitúa en un determinado nivel formal de perfección; el determinado, la materia signata, es por lo que es «este» singular concreto ${ }^{11}$. «La materia recibe la forma para ser constituida por ella en un ser de determinada especie $(\ldots) »^{12}$; de tal suerte que de esta unión resulta una naturaleza determinada ${ }^{13}$. La

tiene tal "esse naturale" que es asimismo "esse intelligibile"; y es claro que, precisamente en la medida en que se identifican por su ser inmaterial la perfección entitativa y la perfección inteligible, una sustancia es actualmente inteligente e inteligible "por esencia"»; CANALS, F., «El "lumen intellectus agentis" en la Ontología del conocimiento de santo Tomás» en Cuestiones de Fundamentación, Publicacions i Edicions Universitat de Barcelona, Barcelona, 1981, p. 27. Este artículo fue publicado por primer vez en Convivum, 1956 (1). Cfr. Sobre la esencia del conocimiento, p. 107.

9 Tomás de Aquino, Summa Theologiae, I, q. 57, a. 1, ad 2.

10 Cfr. Bofill, J., «Para una metafísica del sentimiento» en Obra filosófica, Ariel, Barcelona, 1967, p. 128, n. 38.

11 «Ad primum ergo dicendum quod differentia est quae constituit speciem. Unumquodque autem constituitur in specie, secundum quod determinatur ad aliquem specialem gradum in entibus, quia species rerum sunt sicut numeri, qui differunt per additionem et subtractionem unitatis, ut dicitur in VIII Metaphys. In rebus autem materialibus aliud est quod determinat ad specialem gradum, scilicet forma, et aliud quod determinatur, scilicet materia, unde ab alio sumitur genus, et ab alio differentia. (...)»; Tomás de Aquino, Summa Theologiae, I, q. 50, a. 2, ad 1. La cursiva es mía. Cfr. Forest, A., La structure méthaphysique du concret selon saint Thomas d'Aquin, Vrin, París,1956.

12 Tomás de Aouino, Summa Theologiae, I, q. 50, a. 2, ad 2.

13 Cfr. Tomás de Aouino, Summa Theologiae, I, q. 50, a. 2, ad 3. 
naturaleza o esencia del ente corpóreo asume los dos principios. Aunque la forma tiene prioridad absoluta sobre la materia, ambas se requieren mutuamente.

Debido a la diferencia entre aquello por lo que el ente posee determinado grado de perfección formal, y aquello por lo que es este individuo, el ente corpóreo sólo es inteligible en potencia. En efecto, en virtud de la composición materia-forma, no es posible identificar sin más el supuesto y la esencia, «lo que es» y aquello "por lo que es» el ente ${ }^{14}$. "La quididad del compuesto no es "aquello que es" (ipsum quod est), sino "aquello que es algo" (hoc quod alquid est), como el hombre es por la humanidad» ${ }^{15}$. La expresión «aquello que algo es», manifiesta el carácter compuesto del ente. Así, tenemos que "esta cosa" no es su esencia, resultando paradójicamente que «al juzgar de las cosas según lo que son, parece conmoverse ya el principio de no contradicción por cuanto esta cosa no es su "lo que es" ${ }^{16}$. "Lo que la cosa es» ${ }^{17}$, "aquello por lo cual una cosa ha de ser tal cosa» ${ }^{18}$, que es lo entendido por el entendimiento, difiere realmente del subsistente. A saber, el hombre concreto, Sócrates, es sujeto de actos que no proceden de la razón de humanidad ${ }^{19}$; esto es, cuando se entiende "hombre», no se entiende que sea blanco, alto, o que pertenezca a una determinada época; se entiende, sin embargo, que posea todas estas notas o determinaciones de un modo indeterminado ${ }^{20}$. En esta línea, el concreto o subsistente, en un sentido material, es más extenso que el universal.

En razón de esta inidentidad, el supuesto no puede ser objeto de intelección. A esto se refiere santo Tomás cuando afirma que la sustancia primera no es ni directa ni indirectamente entendida ${ }^{21}$. Si bien el entendimiento puede conocer

14 Cfr. Tomás de Aquino, Contra Gentes, II, 54.

15 Tomás de Aouino, In II Sententiarum, d. 3, q. 1., a. 1. "Unde dicit Avicenna quod quiditas compositi non est ipsum compositum, cuius est quiditas, quamvis etiam ipsa quiditas sit composita, sicut humanitas, licet sit composita, non est homo, immo oportet quod sit recepta in aliquo quod est materia designata. Sed quia, ut dictum est, designatio speciei respectu generis est per formam, designatio autem individui respectu speciei est per materiam, ideo oportet ut nomen significans id, unde natura generis sumitur, cum praecisione formae determinatae perficientis speciem significet partem materialem totius, sicut corpus est pars materialis hominis»; Tomás de Aouino, De ente et essentia, c. 2.

16 F, Canals, «Sobre el punto de partida y el fundamento de la metafísica» en Cuestiones de Fundamentación, Publicacions i Edicions Universitat de Barcelona, Barcelona, 1981, p. 105. Este escrito fue publicado por primera vez con el nombre «Fundamentación de la metafísica», PPU, Barcelona, 1968. Cfr. Tomás DE Aquino, In III De Anima, lect. 8.

17 Tomás de Aquino, De ente et essentia, c. 1.

18 Tomás de Aouino, De ente et essentia, c. 1.

19 Cfr. Tomás de Aouino, De potentia, q. 7, a. 4.

20 «Secundum hoc ergo, cuicumque potest aliquid accidere quod non sit de ratione suae naturae, in eo differt res et quod quid est, sive suppositum et natura. Nam in significatione naturae includitur solum id quod est de ratione speciei; suppositum autem non solum habet haec quae ad rationem speciei pertinent, sed etiam alia quae ei accidunt; et ideo suppositum signatur per totum, natura autem, sive quidditas, ut pars formalis»; TomÁs DE Aquino, Quolibet, II, q. 2, a. 2. Cfr. Compendium Theologiae, lect. 1, c. 10.

21 Cfr. Tomás de Aquino, Summa Theologiae, I, q. 86, a. 7. 
en concreto lo que conoce en abstracto por una vuelta a la imagen ${ }^{22}$, este conocimiento no lleva consigo una aprehensión del singular a modo de objeto ${ }^{23}$. La razón de esta cuestión ha sido lúcidamente expresada por Canals: lo material se encuentra en su misma sustancialidad individual «intrínsecamente modificado y singularizado por principios infraesenciales, cuantitativos y materiales, que se comportan respecto de la forma constitutiva de una sustancia y de todas sus determinaciones cualitativas propias, en una línea de receptividad "subjetiva" y contingente ${ }^{24}$. La verdad inteligible de la «cosa», por tanto, queda como escindida de su realidad como subsistente ${ }^{25}$. En esto se cifra precisamente la distinción entre el esse naturale y el esse inteligibile del ente corpóreo: «el orden de lo sensible queda en su facticidad y contingencia "fuera" o "por debajo" de la inteligibilidad y de la verdad ${ }^{26}$ del ente. Para el hombre, sólo lo universal puede ser directamente aprehendido por el entendimiento. Esta determinación a lo universal del entendimiento no es sino el correlato de la no inteligibilidad intrínseca del singular sensible ${ }^{27}$.

Se puede sintetizar lo hasta ahora expuesto afirmando que, el que puedan darse dos individuos pertenecientes a una misma especie, supone que en el individuo A y en el individuo B se den una serie de notas que no modifican, sin embargo, la naturaleza de cada uno de los subsistentes. En efecto, si estas características modificaran al subsistente en su naturaleza, ya no podría darse más de un individuo por especie. Aquello por lo que A se distingue de B no puede ser de la razón esencial de la naturaleza común de A y B. Aquello que

22 Cfr. Tomás de Aouino, Summa Theologiae, I, q.12, a. 4, ad 3.

23 Cfr. Canals, F., «Verdad trascendental y subsistencia espiritual en Santo Tomás», p. 185. «La conversión a la imagen es "como una reflexión", en el sentido de que por ella el mismo sujeto que entiende lo universal es consciente de su propio conocimiento sensible, y de la originación de las imágenes de su acto de intelección directa. Mediante esta conciencia puede referir lo que entiende, es decir, lo universal, a lo singular percibido y representado en las imágenes, en las que la actividad del entendimiento agente había iluminado las "especies impresas", es decir, el principio subjetivo especificante de su aprehensión intelectual objetiva»; «Verdad trascendental y subsistencia espiritual en Santo Tomás», p. 185.

24 Canals, F., Sobre la esencia del conocimiento, p. 113. «Un singular material, en cuanto tal, no ofrece en su misma singularidad una coherencia esencial del conjunto de sus determinaciones, antes, por el contrario, se constituye en un sujeto del que podrían enunciarse, en la línea del sobrevenir accidental, indeterminadamente, múltiples enunciaciones, precisamente por estar cruzado en su misma substancialidad individual por principios constitutivos no correlacionados entre sí esencialmente»; Canals, F., Sobre la esencia del conocimiento, p. 114. Toda "essentia" de un ente material es una esencia "abierta", y de ninguna manera una unidad absoluta de inteligibilidad, una "esencia en sî", si vale la expresión, una "idea"; BofiLl, J., «Para una metafísica del sentimiento», p. 114, nota 19.

${ }_{25}$ Cfr. Canals, F., «Verdad trascendental y subsistencia espiritual en Santo Tomás», p. 186.

26 CANALS, F., «Verdad trascendental y subsistencia espiritual en Santo Tomás», p. 186: «La síntesis aristotélica quiere ser precisamente la superación de esta aporía. Al afirmar el carácter de "pura potencia" en la línea de la esencia, que tiene la materia, busca sintetizar la facticidad contingente de lo singular sensible con la verdad de su esencia universal».

27 Cfr. Canals, F., «Verdad trascendental y subsistencia espiritual en Santo Tomás», p. 184. 
es propio y distinto del ente corpóreo se comporta respecto de aquello que es común como lo receptivo y contingente se comporta respecto de lo formal y necesario. En el ente corpóreo, singularidad y accidentalidad se exigen mutuamente. Todo individuo perteneciente a una especie posee accidentes que no pertenecen a la razón esencial de ésta. A saber, no hay una razón esencial que determine la relación de la substancia con cada uno de los accidentes que le pueden advenir. En efecto, los accidentes que acompañan a la substancia corpórea en cuanto corpórea no son de la razón esencial de ésta.

\section{4. «INFINITUD» DE UNA FORMA SEPARADA}

La inteligibilidad en acto de una forma separada es justificada por santo Tomás en la relación que guarda ésta con su acto de ser. En efecto, el Aquinate sostiene que las inteligencias separadas son "éstas» por la misma forma que le da el ser, no por «algo» distinto de ellas ${ }^{28}$. Esto es, en razón de que son subsistentes, «no es posible presuponer algo por lo que sean tales individualmente ${ }^{29}$. Por un mismo principio, la forma, las substancias separadas poseen determinada perfección ontológica y son individuales. Para expresar esta cuestión santo Tomás recurre a diversas fórmulas, una de ellas reza así: «la individuación no proviene de materia individual, quiero decir, de "esta” materia, sino que las formas son individuales por sí mismas ${ }^{30}$.

La autarquía de una forma subsistente en orden a su individualización refiere a una más perfecta participación en el ser, a la identidad entre «lo que es» y «aquello por lo que es» el ente. En efecto, como precisa Santo Tomás, «el ser le compete por esencia a la forma que es acto ${ }^{31}$. "La forma, comparada con el ser, es como la luz con la iluminación o la blancura con el hecho de blanquear ${ }^{32}$. Esto es, la esencia es el medio por el cual el esse se manifiesta; de aquí que los

28 «In substantia autem immateriali non potest praeintelligi aliquid per quod sit haec, quia est haec per suam formam, per quam habet esse, cum sint formae subsistentes»; Toмís De Aouino, Summa Theologiae, I, q. 45, a. 5, ad. 1.

29 Tomás de Aouino, Summa Theologiae, I, q. 45, a. 5, ad 1.

30 Tomás de Aouino, Summa Theologiae, I, q. 3, a. 3. «(...) non tamen accidunt eis aliqua quae sunt determinativa essentiae speciei: quia ipsa natura speciei non individuatur per materiam, sed per seipsam, ex hoc quod talis forma non est nata recipi in aliqua materia; unde per se ipsam non est multiplicabilis, neque praedicabilis de pluribus»; TomÁs DE Aquino, Quolibet, II, q. 2, a. 2, ad. 1. Es doctrina ya está presente en el Comentario a las sentencias: «sed Angelus in natura sua simplici nullo indigens partium vel materiae fundamento»; ToMÁs DE Aquino, In II Sententiarum, d. 3, q. 1, a. 2.

31 Tomás de Aquino, Summa Theologiae, I, q. 75, a. 6. «Videmus enim quod res materiales referuntur ad causam primam ut accipiant esse ab ea per suam formam; et ideo substantia cuius tota essentia est forma, habet per seipsam relationem semper ad causam suam et non causatur ista relatio in huiusmodi substantiam per aliquam aliam formam»; ToMÁs DE AoUINo, In De Causis, lect. 26. Las cursivas son mías.

32 Tomás de Aquino, Contra Gentes, II, 54. 
principios esenciales de la forma queden perfectamente prescritos ${ }^{33}$ : todo en ella es inteligible. Si bien el esse no es una propiedad esencial de la forma, no introduce accidentalidad en el subsistente.

Esta relación «cuasi» necesaria entre esencia y ser ${ }^{34}$ es la razón de que la substancia inmaterial goce de «cierta infinitud». Tanto en el opúsculo Sobre el ente y la esencia, en la Exposición sobre el "Libro de las causas», como en el opúsculo Sobre las substancias separadas, afirma el Aquinate que «toda forma simple es infinita ${ }^{35}$. Esta infinitud es una perfección participada y se funda en la participación trascendental del $\operatorname{ser}^{36}$. Señala al respecto santo Tomás: «toda forma, en su razón propia, si se considera abstractamente, tiene infinitud; como sucede en la blancura, abstractamente considerada, su razón de blancura no está limitada a una cosa; y, sin embargo, la razón de color y la razón de ser se determina en ella y se contrae a una determinada especie» ${ }^{37}$. Nada hay en la razón de forma por la que ésta ha de estar limitada. Lo indeterminado en la razón de blanco tomada abstractamente, siguiendo con el ejemplo presentado por santo Tomás, es precisamente la cantidad virtual de perfección «color blanco». Si la forma «color blanco» se encuentra recibida en un sujeto, a no ser que éste sea a su vez un infinito actual, será una forma contraída. En efecto, es metafísicamente imposible que una potencia pasiva iguale al acto por ella participado ${ }^{38}$. La forma participada estará limitada y finitizada según sea la capacidad de su recipiente ${ }^{39}$.

33 Cfr. Tomás de Aquino, Quolibet, II, q. 2, a. 2, ad. 1.

34 Como explica Fabro, santo Tomás aproxima en el orden predicamental «forma y esse hasta la correspondencia inmediata, y, por, consiguiente, hasta la afirmación de la derivación intrínseca del esse de la forma»; FABro, C., Participación y causalidad según Tomás de Aquino, Eunsa, Pamplona, 2009, p. 318.

35 Cfr. Neuman, M. R., Metafísica de la inteligibilidad y la autoconciencia en Tomás de Aquino, Eunsa, Pamplona, 2014, primera parte, capítulo 2.

36 Lúcidamente afirma De Finance, «una perfección pura sólo se presenta como "infinita" si se ve en ella una expresión de la perfección radical del esse. (...) Por lo demás, incluso en el plano formal, el principio de ilimitación (o mejor de perfección) implica la consideración del esse. En efecto, dicho principio se enuncia del acto en cuanto existente (o, al menos ordenado a la existencia). La posición existencial, idealmente efectuada en la afirmación, convierte la indeterminación por defecto en una determinación por exceso, en una ilimitación»; J. De Finance, Conocimiento del ser. Tratado de ontología, Madrid, Gredos, 1971, p. 345. «Por esto la infinitud no podría aparecer nunca en la línea de la esencia entendida como consistencia y estabilidad de las cosas, y como aquello que tiene el ser, sino que sólo puede ser pensada en la línea de aquél término superior a que se refieren, y que es lo determinante y actual del ente en cuanto ente»; CANALS, F., "El "Ipsum esse subsistens" como esencia metafísica de Dios» en Cuestiones de Fundamentación, Publicacions i Edicions Universitat de Barcelona, Barcelona, 1981, p. 211.

37 Tomás de Aquino, In I Sententiarum, d. 43, q. 1, a. 1. «Sicut si diceremus albedinem separatam existentem esse infinitam quantum ad rationem albedinis, quia non contrahitur ad aliquod subiectum; esse tamen eius esset finitum, quia determinatur ad aliquam naturam specialem (...)»; Tomás de Aouino, Summa Theologiae, I, q. 50, a. 2, ad 4.

38 Cfr. Tomás de Aquino, Contra Gentes, I, 43.

39 Cfr. Tomás de Aquino, In De divinis nominibus, c. V, lect. 1. 
Ahora bien, las formas naturales que informan a los entes corpóreos substancialmente no poseen una perfección que pueda ser graduada según un más y un menos. Esto es, la forma substancial caballo, si se considera abstractamente, no puede ser considerada como poseyendo más perfección que la que se da en cada caballo concreto: cada caballo participa de toda la razón formal de caballo. Sin embargo, la forma de caballo que no fuera recibida en un sujeto habría de ser en algún sentido infinita; habría de subsistir como presente para sí, ser patente al espíritu en su individualidad. La infinitud inferior de una forma subsistente, por tanto, debe ser pensada en términos de "autopresencialidad». Una forma que ha sido recibida en la materia es una forma que se encuentra referida a algo distinto de sí; una forma que es subsistente, vuelve sobre su propia esencia. En efecto, la forma «en cuanto perfecciona a la materia dándole el ser, se difunde por ella, y, en cambio, por cuanto retiene el ser, se repliega sobre sí misma» ${ }^{40}$. El grado de dispersión de la forma vendrá dado por la relación o dependencia que guarde respecto de la materia.

\section{INTELIGIBILIDAD INTRÍNSECA}

Se puede encontrar en la obra de santo Tomás un detallado estudio sobre el conocer angélico. La completa inmaterialidad de una forma separada, y, por tanto, su existir en acto en el género de lo inteligible, presentan un nuevo horizonte de reflexión acerca del modo en que un ser inteligente puede acceder al conocimiento de sí, de Dios y del resto de los entes creados.

Ya hemos hecho referencia al autoconocimiento de una forma separada: un ángel siempre se está entendiendo a sí mismo por su propia esencia. Interesa resaltar en relación a esta cuestión que en el ángel no hay, propiamente, entendimiento paciente ${ }^{41}$. La existencia de un entendimiento tal da cuenta de un ámbito de indeterminación y pasividad cognoscitiva que no es propia de un ser que existe como acto en el género de lo inteligible. Si bien el ángel requiere

40 Tomás de Aquino, Summa Theologiae, I, q. 14, a. 2, ad 1. La cursiva es mía. «Omne quod secundum operationem ad seipsum est conversivum, et secundum substantiam est ad se conversum. Quartam propositionem sumamus XLIV (propositionem) libri eius: omne quod secundum operationem ad seipsum est conversivum, et secundum substantiam est ad se conversum. Et hoc probatur per hoc quod, cum converti ad seipsum sit perfectionis, si secundum substantiam ad seipsum non converteretur quod secundum operationem convertitur, sequeretur quod operatio esset melior et perfectior quam substantia»; Tomás DE Aouino, In De Causis, lect. 15. La cursiva en mía.

${ }_{41}$ «El finito conocimiento intelectual intuitivo no puede ser denominado intellectus possibilitis, porque un ser así se encuentra cabe sí mismo de por sí mismo y no llega a sí mismo por recepción de algo otro que de por sí mismo se muestra»; RaHner, K., El espíritu en el mundo. Metafísica del conocimiento según santo Tomás de Aquino, Editorial Herder, Barcelona, 1963, p. 240. 
de especies innatas que le permitan conocer lo otro que sít ${ }^{42}$ y en este sentido le compete «padecer», su entendimiento nunca se encuentra desprovisto de éstas. Las especies que posee de todo lo creado, las posee desde el momento de su creación. En efecto, afirma santo Tomás que el entendimiento angélico se asemeja a «una tabla pintada o a un espejo en el que resplandecen las nociones de todas las cosas» ${ }^{43}$. Todo lo que pudiera estar en un entendimiento tal en potencia, está, desde el momento de su creación, en acto ${ }^{44}$ : «las formas que han sido impresas por Dios en las cosas, para que subsistan, han sido impresas en el ángel para que las conozca ${ }^{45}$. Siendo metafísicamente imposible que un entendimiento entienda a la vez una pluralidad de especies, el ángel posee de todas una noticia habitual ${ }^{46}$. Esto es, puede conocerlo todo sin tener que pasar en términos absolutos de la potencia al $\mathrm{acto}^{47}$.

Existe una relación necesaria entre tener un entendimiento potencial, y que el principio por el cual se esté en acto de entender sea extrínseco. Así, mientras que el intelecto humano está naturalmente determinado a la forma inteligible que es abstraída de los sentidos, la facultad natural del ángel lo está a la «forma inteligible no recibida del sentido, y principalmente a la forma que es su esencia ${ }^{48}$. La potencialidad intelectual del hombre es resueltamente afirmada por el Aquinate: el entendimiento «es sólo capacidad de entender, teniendo por ello, de suyo, el poder de entender, mas no el de ser entendido mientras no se constituya en acto ${ }^{49}$. A saber, antes de ser actualizado, el entendimiento humano se encuentra en pura potencia respecto de los seres inteligibles ${ }^{50}$, como la materia prima respecto de las formas inteligibles. A esta cuestión hace alusión la célebre afirmación de Aristóteles: el entendimiento humano es como tabula rasa, como una pizarra en la que nada hay escrito ${ }^{51}$.

A partir de esta constatación, Canals hace una observación que nos parece pertinente considerar. En virtud de su potencialidad cognoscitiva, señala, la

42 Cfr. Tomás de Aquino, Summa Theologiae, I., q. 84, a. 2; q. 87, a.1; I-II, q. 50, a. 6; q. 51, a. 1, ad 2; In II Sententiarum, d. 3, q. 2, a.1; De veritate, q. 8, a. 8; Contra Gentes, II, 98. SuAREzNANI, T., Connaissance et langage des anges selon Thomas d'Aquin et Gilles de Rome, Librairie Philosophique J. Vrin, Paris, 2002, p. 25.

43 Tomás de Aquino, De veritate, q. 8, a. 9. Cfr. Summa Theologiae, I, q. 55, a. 2.

44 Cfr. Tomás de Aouino, Contra Gentes, II, 98; De veritate, q. 8, a. 15.

45 Tomás de Aquino, In II Sententiarum, d. 3, q. 3, a. 1, ad 2.

46 Cfr. Tomás de Aquino, De malo, q. 16, a. 6, ad 4.

47 Cfr. Tomás de Aquino, In De Trinitate, pars 1, q. 1, a. 1, ad4.

48 Tomás de Aquino, De veritate, q. 8, a. 3. La cursiva es mía.

49 Tomás DE Aquino, Summa Theologiae, I, q. 87, a. 1. "Quaedam autem virtus cognoscitiva est quae neque est actus organi corporalis, neque est aliquo modo corporali materiae coniuncta, sicut intellectus angelicus. Et ideo huius virtutis cognoscitivae obiectum est forma sine materia subsistens, etsi enim materialia cognoscant, non tamen nisi in immaterialibus ea intuentur, scilicet vel in seipsis vel in Deo»; Tomás DE Aquino, Summa Theologiae, I, q. 85, a. 1

50 Cfr. Tomás de Aouino, Summa Theologiae, I, q. 87, a. 1; q. 14, a. 2, ad 3; De veritate, q. 8 , a. 7; q. 10, a. 8; q. 18, a. 7; Contra Gentes, II, 75; II, 98; De anima, a. 16, ad 8. Son algunos de los pasajes en que el Aquinate trata esta cuestión.

51 Cfr. Tomás de Aquino, In III De Anima, lect. 9. 
existencia en el hombre tendrá «necesidad de un despliegue perfectivo en el que deberá abrirse al ente universal que le trasciende a modo de objeto y se percibirá a sí misma como "subjetiva" „" ${ }^{52}$. Si bien el entendimiento de una forma separada no se encuentra en acto perfecto respecto al ente universal ${ }^{53}$, el existir angélico no se da al modo de «un despliegue perfectivo».

Para alcanzar su perfección cognoscitiva, en términos absolutos, tanto el hombre como el ángel deben «recibir», esto es, adquirir algo que no les conviene de modo esencial: las especies de lo otro que sí. Precisa al respecto santo Tomás: «al entendimiento angélico no le pertenece, por su misma naturaleza y capacidad, conocer todas las cosas, pues necesitaría ser acto de todas ellas $»^{54}$. En este sentido, es apropiado afirmar que el entendimiento del ángel "padece ${ }^{55}$. Ahora bien, la potencialidad intelectual de una forma separada no debe ser equiparada sin más a la del alma humana. La potencialidad intelectual de un ángel supone formalmente distinción entre aquello que éste posee por naturaleza, la intelección en acto de su propia esencia, de aquello que le adviene como un además, las especies innatas con las que conoce lo distinto de $s^{56}$. Al estar la potencialidad cognoscitiva de una forma separada subsanada desde el mismo momento de su creación, no es necesario que se dé en ella un «despliegue perfectivo». La potencialidad cognoscitiva del hombre, en cambio, nunca deja de ser tal en esta vida: su entendimiento siempre estará abierto a recibir nuevas formas inteligibles ${ }^{57}$.

Volviendo a la cita de Canals, interesa resaltar que, dada su potencialidad cognoscitiva, la existencia del hombre «deberá abrirse al ente universal que le trasciende a modo de objeto y se percibirá a sí misma como "subjetiva" ». En el ángel, puesto que existe en acto en el género de lo inteligible, esta apertura no es algo «a realizar». Su actualidad intelectual consiste justamente en un «ininterrumpido estar en el ser». En efecto, glosando a santo Tomás, Canals señala que «nadie puede tener conciencia de que piensa y existe sin estar en el acto mismo pensando el ente universal como objeto y poniéndose a sí mismo "en el

52 Cfr. Canals, F., «Sobre el punto de partida y el fundamento de la metafísica», p. 127.

53 Intellectus enim, sicut supra dictum est, habet operationem circa ens in universali. Considerari ergo potest utrum intellectus sit in actu vel potentia, ex hoc quod consideratur quomodo intellectus se habeat ad ens universale. Invenitur enim aliquis intellectus qui ad ens universale se habet sicut actus totius entis, et talis est intellectus divinus, qui est Dei essentia, in qua originaliter et virtualiter totum ens praeexistit sicut in prima causa. Et ideo intellectus divinus non est in potentia, sed est actus purus. Nullus autem intellectus creatus potest se habere ut actus respectu totius entis universalis, quia sic oporteret quod esset ens infinitum»; Tomís de Aouino, Summa Theologiae, I, q. 79, a. 2.

54 Tomás de Aquino, Summa Theologiae, I-II, q. 51, a. 1, ad. 2.

${ }_{55}$ Cfr. Neuman, M. R., Metafísica de la inteligibilidad y la autoconciencia en Tomás DE Aquino, p. 111.

56 Cfr. Neuman, M. R., Metafísica de la inteligibilidad y la autoconciencia en Tomás DE Aquino, p. 113.

57 Cfr. Tomís de Aouino, Contra Gentes, II, 98. El alma humana se asemeja a los cuerpos inferiores: la forma substancial de estos nunca colma toda la potencialidad de la materia; cfr. Tomás de Aquino, In De Causis, lect. 10. 
ser" $»^{58}$. Al aprehender su propia esencia sub ratione entis, el ángel queda «instalado» en el ser de forma tal que no puede sino existir «sabiéndose ser». Aunque perciba su existencia como «finita», no se le patentiza como «subjetiva», esto es, como potencial en la línea de la actualidad intelectual.

\section{TRAscedentalidad DE LA LUZ INTELigiBle}

En In II Sententiarum precisa santo Tomás que el intelecto agente está en los ángeles y en nosotros de diversas maneras: «Así pues, el intelecto agente de ellos siempre está en acto, porque incesantemente luce en los ángeles para considerar algo en acto; y lo mismo ocurre con nosotros, guardando las distancias; mas no es preciso que se produzca la orientación a una sola especie, de tal manera que siempre entienda en acto» ${ }^{59}$. El entendimiento agente del ángel, por tanto, siempre está en acto, y está orientado a una sola especie. Sólo la primera de éstas afirmaciones se puede aplicar al entendimiento agente del hombre. Aquello a lo que está orientado el entendimiento angélico es a su propia esencia, y por esto «la mente del ángel siempre entiende actualmente» ${ }^{60}$. El entendimiento del hombre, en cambio, no está intrínsecamente determinado a iluminar una determinada realidad, por lo mismo, no está siempre en acto entendiendo. Su entendimiento se constituye en acto al entender alguna especie inteligible respecto de la cual no guarda relación necesaria. Puede entender la especie de un ente u otro de modo indiferenciado. En efecto, «la intelección de este o aquel objeto pertenece como tal a la contingencia del curso concreto de la vida de cada hombre ${ }^{61}$. En el conocimiento que el ángel tiene de sí, en cambio, la intelección de la propia esencia está en el orden esencial. Ésta, no es un elemento más a inteligir, sino lo primero conocido y principio de todo otro conocer $^{62}$.

Si bien no cabe duda de que estar siempre entendiendo es más perfecto que entender de un modo intermitente, la determinación de la esencia angélica a una sola especie se puede antojar restrictiva. En efecto, en el hombre, como señala Leonardo Polo, «la operación de conocer y conocido se conmensuran estrictamente» ${ }^{63}$; a saber, «tanto acto, tanto conocido; tanto conocido, tanto

\footnotetext{
58 Canals, F., Sobre la esencia del conocimiento, p. 475.

59 Tomás de Aquino, In II Sententiarum, d. 3, q. 3, a. 4, ad 4.

60 Tomás de Aquino, De veritate, q. 8, a. 14, ad 6. «La diferencia entre un espíritu encarnado y otro no encarnado se encuentra en que su operación natural, la que no puede fallar, y que en este caso no le abandona en momento alguno, porque no hay ninguna causa posible que la impida, es la que versa sobre sí mismo». Murillo, J. I. , Operación, hábito y reflexión. El conocimiento como clave antropológica en Tomás de Aquino, Eunsa, Pamplona, 1998, p. 203.

${ }_{61}$ CANALS, F., «Sobre el punto de partida y el fundamento de la metafísica», p. 125

62 Cfr. Tomás de Aouino, Contra Gentes, III, 46.

63 Polo, L., Curso de Teoría del conocimiento (I), p. 80.
} 
acto» ${ }^{64}$. En este sentido, sigue el mismo autor, «el objeto mide» ${ }^{65}$. No puede haber un acto de conocimiento «ciego», que no sea «conocer algo»; ni «más conocido que lo que se conoce por la operación» ${ }^{66}$. Así, si el entendimiento humano estuviese orientado a una sola especie de modo necesario, el hombre no tendría propiamente horizonte cognoscitivo, su entender se vería clausurado, imposibilitado de trascenderse en la determinación a una sola esencia que hace las veces de límite cognoscitivo. Ni siquiera podría saberse cognoscente. La cuestión que se nos plantea, por tanto, es ¿cómo el ángel, estando determinado a una sola razón inteligible, mantiene su apertura cognoscitiva?

La respuesta a esta cuestión vendrá dada no por la puesta en entredicho de la conmensuración entre operación y objeto, sino por la profundización en la naturaleza cognoscitiva de un inteligible intrínseco. El conocimiento que el ángel tiene de sí no se constituye desde la relación sujeto-objeto. En efecto, como acertadamente observa Canals, «lo esencial en cuanto objeto es lo proporcionado al espíritu en cuanto sujeto, es decir en cuanto potencial en la línea de la actualidad y perfección inteligible ${ }^{67}$. El hombre tiene un entendimiento pasivo, y, por tanto, una dimensión subjetiva, por ocupar el último lugar en el género de lo inteligible. Para que se dé la proporción sujeto-objeto, se requiere de una parte, «la potencialidad del sujeto en su naturaleza intelectual» ${ }^{6}, \mathrm{y}, \mathrm{de}$ otra, el carácter «extrínseco al orden de lo inteligible propio de las cosas «extra intellectum ${ }^{69}$. Entre uno y otro elemento existe una relación necesaria: "si el entendimiento humano tiene como objeto propio y "primero" — primero y propio en la línea de la objetividad- la esencia de las cosas materiales, es en razón de su carácter de "potencia» ${ }^{70}$. En una forma separada no se cumple ninguno de los requisitos: el ángel 1) siempre está en acto entendiendo, y 2) su objeto propio es lo inteligible en acto.

Se debe considerar detenidamente el alcance de la existencia de un «inteligible en acto». En primer lugar, se ha de señalar que, como insistió Cayetano, si la esencia angélica es intrínsecamente inteligible, no ha de estar en el entendimiento como recibida, como especie que actúa o informa a una facul$\operatorname{tad}^{71}$. Este es el esquema específico para un entendimiento que tiene un ámbito de potencialidad intelectual. Al estar como recibida, la especie establece con la facultad cognoscitiva una relación accidental: el entendimiento es libre de

64 Polo, L., Curso de Teoría del conocimiento (I), p. 80.

65 Polo, L., Curso de Teoría del conocimiento (I), p. 80.

66 Polo, L., Curso de Teoría del conocimiento (I), p. 80.

67 Canals, F., "Verdad trascendental y subsistencia espiritual en Santo Tomás», p. 188.

68 Canals, F., "Verdad trascendental y subsistencia espiritual en Santo Tomás», p. 188.

69 Canals, F., «Verdad trascendental y subsistencia espiritual en Santo Tomás», p. 188.

70 Canals, F., "Verdad trascendental y subsistencia espiritual en Santo Tomás», p. 188.

71 Cfr. Canals, F., Sobre la esencia del conocimiento, p. 461. Rahner ha sabido expresar adecuadamente esta cuestión: «tal intelectualidad intuitiva no es, por tanto, receptiva, pues su “objeto" es su propio ser y éste no se "opone", ni tiene por qué mostrarse de por si al intelecto, pues tampoco tiene la posibilidad de ocultarse a él»; RAHNER, K., El espíritu en el mundo, p. 240. 
atender a ésta u aquella especie. Conocida tal realidad, puede dejar de considerarla; más aún, ha de dejar de considerarla para pasar a considerar otra. El entendimiento de una forma separada, en cambio, no guarda esta «liberalidad» respecto de su principio intrínseco de actualidad. Está siempre orientado a una sola especie: su propia esencia. Traspasar el esquema de pasividad-actualidad propio del hombre a un inteligible intrínseco constituye un grave error. En efecto, ni la esencia angélica ni las especies innatas de lo otro que sí están en el entendimiento del ángel propiamente como «recibidas» ${ }^{72}$.

Santo Tomás explica la naturaleza de un inteligible intrínseco afirmando que es «como si la luz se viese en el ojo» ${ }^{73}$. Para evitar que esta imagen haga referencia a la relación sujeto-objeto, me atrevo a sugerir que es más apropiado afirmar que es como si del ojo brotara una luz que lo tornara visible y vidente en acto. En efecto, la esencia de una forma separada es intrínsecamente «luminosa ${ }^{74}$. La especie que informa al entendimiento del hombre, en cambio, no tiene luz en sí; ella es lo «iluminado». Como es patente, en lo iluminado, «luz»y «contenido» son discernibles. En el acto de conocimiento de un hombre, una cosa es la luz con la que conoce, y otra lo conocido. Lo iluminado es lo «presente» a la conciencia ${ }^{75}$ : «una forma no puede darse, en el ser inmaterial por el que es actualmente inteligible, sino como contenido del "acto" de una conciencia» ${ }^{76}$.

Lo intrínsecamente luminoso, por su parte, designa «inmediatez luminosa» ${ }^{77}$. Esto es, el ángel no se encuentra respecto de sí como si estuviese «iluminando a un objeto $»^{78}$. Recordemos que «la forma, comparada con el ser, es como la

72 Cfr. Neuman, M. R., Metafísica de la inteligibilidad y la autoconciencia en Tomás de Aquino, p. 182.

73 Tomás de Aouino, Summa Theologiae, I, q. 56, a 3.

${ }^{74}$ Para santo Tomás el nombre de luz se dice más propiamente de las cosas espirituales que de las sensibles. Cfr. Tomás de Aouino, Super Ioannem, c. 1, lect. 3. González Ayesta precisa que santo Tomás utiliza el término lumen en relación a cuatro realidades: «el intelecto agente (lumen intellectus agentis), la fe (lumen fidei), la visión profética (lumen propheticum) y la visión beatíifca (lumen gloriae)». "El intelecto agente en santo Tomás» en Actes du XI Confrès International de Philosophie Médiévale de la Socitété Internationale pour l'Étude de la Philosophie Médiévale (S.I.E.P.M), Oporto, 2002, p. 141.

75 «Un objeto abstracto es siempre un objeto presente». Polo, L., Curso de teoría de conocimiento II ( $3^{\mathrm{a}}$ ed.), Eunsa, Pamplona, 1998, p. 201. «La distinción entre los abstractos (en la misma medida en que se toma en cuenta) equivale a que al conocer un abstracto no se conoce todo: no se conoce todo por cuanto que se conoce otro abstracto»; cfr. Polo, L., Curso de teoría de conocimiento III ( $2^{\mathrm{a}}$ ed.), Eunsa, Pamplona, 1999, p. 25.

76 Canals, F., «El "lumen intellectus agentis" en la ontología del conocimiento de santo Tomás», p. 30.

77 La intelectualidad de las inteligencias separadas «es sinónimo de transparencia y de inmediatez»; SuAREZ-NanI, T., Connaissance et langage des anges selon Thomas d'Aquin et Gilles de Rome, p. 24.

78 Cfr. Neuman, M. R., Metafísica de la inteligibilidad y la autoconciencia en Tomás de Aquino, p. 123. 
luz con la iluminación o la blancura con el hecho de blanquear» ${ }^{79}$. Mientras que lo «iluminado» en el orden de lo inteligible es un abstracto universal, lo «luminoso» sólo puede ser un subsistente singular. De aquí que Santo Tomás llame a los ángeles, en cuanto son formas inteligibles en acto, «luminarias» ${ }^{80}$. Para que una realidad comparezca como objeto frente a una conciencia, se requiere que ésta exista en el sujeto sólo «según su razón propia»" ${ }^{81}$ Un inteligible intrínseco, en cambio, existe para sí en esse natural y en esse inteligible.

En el acto de conocimiento de un hombre toda la densidad «iluminadora» de la luz del agente es acaparada por la especie que está siendo actualmente iluminada; de aquí que no quede margen para que comparezca ante él, en el plano esencial, alguna otra realidad. En el acto de (auto)conocimiento de un ángel, en cambio, la propia esencia, puesto que no está respecto de sí como «lo iluminado», no se comporta como límite cognoscitivo. Tal como señala santo Tomás, entendiéndose a sí misma, la mente del ángel puede entender a la vez alguna otra $\operatorname{cosa}^{82}$; de suerte que la propia esencia y la cosa conocida constituyen un solo inteligible. Entre la esencia del ángel y la cosa entendida, por tanto, se da una relación formal: la esencia angélica es la razón de cognoscibilidad de todo lo conocido. En efecto, «si dos cosas se relacionan de manera tal que una sea la razón de entender a la otra, una de ellas será como formal y la otra como material ${ }^{83}$.

Para ejemplificar esta cuestión santo Tomás recurre a la metáfora de la luz: «la luz, en efecto, es aquello por lo que se ve el color, y por eso se relaciona con el color como algo formal, y de esa manera el color y la luz son una sola cosa visible y son vistas a la vez por la mirada ${ }^{84}$. Todo lo que el ángel conoce, lo conoce a partir de su inteligibilidad intrínseca: su esencia es el principio o medio de todo su conocer ${ }^{85}$. El conocimiento que tiene el ángel de lo diverso de sí, por tanto, no constituye su actualidad inteligible, sólo amplía su horizonte cognoscitivo. Las especies innatas no son formas del entendimiento al modo como lo son las especies iluminadas del fantasma que actúan al posible ${ }^{86}$.

Es doctrina asumida por santo Tomás que el alma humana, siendo forma de un cuerpo, vuelve sobre sí, es poseedora del ser por sí. Ahora bien, por ocupar

79 Tomás de Aquino, Contra Gentes, II, 54.

80 Tomás de Aquino De veritate, q. 8, a. 7, ad11.

81 Tomás de Aouino De veritate, q. 23, a. 5.

82 Cfr. Tomás de Aouino, De veritate, q. 8, a. 14, ad 6. Conociéndose directamente a sí misma, una forma separada puede conocer a la vez otra realidad. Siempre que una forma separada conoce, «conoce desde el más alto principio de su conocer: la inteligibilidad en acto de su esencia. Cualquier realidad que pueda conocer la conoce como entendida en sí y desde sí»; Murillo, J. I., Operación, hábito y reflexión, p. 204. La cursiva en mía.

83 Tomás de Aquino, De veritate, q. 8, a. 14, ad 6.

84 Tomás de Aquino, De veritate, q. 8, a. 14, ad 6.

85 Cfr. Tomás de Aouino, De veritate, q. 8, a. 14, ad 6.

86 «Species autem a phantasmatibus accepta non est forma substantiae separatae ut per eam cognosci possit, sicut per eam aliqualiter cognoscitur intellectus possibilis»; TOMÁs DE Aouino, De anima, a. 16, ad 8. 
el último lugar dentro del orden de los inteligibles, la luz del entendimiento agente, como trataremos en el siguiente apartado, no es sino indirectamente cognoscible. En esto se diferencia de la luz de una substancia separada. Ahora bien, una y otra tienen en común su carácter trascendental: trascienden toda determinación específica. Tal como señala Canals, la autopresencia e indistinción respecto de sí misma, ordena a la forma inmaterial a participar del ser según un modo perfecto en el que «no se acorta y deprime la presencia del acto a sí mismo ${ }^{87}$. En virtud de su inmaterialidad, la forma separada es constituida «en connatural conexión con todo ente según que tiene ser» ${ }^{88}$. El entendimiento agente, en cuanto que es una realidad espiritual, participa analógicamente de esta perfección: es capaz de infinitas semejanzas de otros ${ }^{89}$. Afirma al respecto el Aquinate: «con el intelecto agente no se conocen todas las cosas como si fuese una semejanza suficiente para conocerlas todas, por el hecho de que no hay un acto de todas las formas inteligibles en cuanto a esta o aquella forma, sino solamente en cuanto que son inteligibles» ${ }^{90}$.

Respecto a cualquier determinación específica, la luz del intelecto es lo formal. Esta cuestión ha sido vista con claridad por Polo: «el intelecto agente no se confunde con los inteligibles en acto ni se agota en ellos» ${ }^{91}$. En efecto, una cosa es la luz y otra lo iluminado por ella. Ningún contenido en el ámbito del ente finito conmensura la extensión de la luz inteligible. Lo iluminado por el entendimiento, no obstante, concentra en sí toda la luminosidad del agente; por esto, decíamos, éste no se puede extender a más de un inteligible a la vez. Se debe distinguir, precisa Polo, lo inteligido en acto y el intelecto como acto, para asegurar que el intellectus ut co-actus no sea oscurecido, no pierda su interna diafanidad. Diafanidad «desde la cual puede serlo todo al dar lugar a la iluminación de ello» ${ }^{92}$. La metáfora de la luz, por tanto, da cuenta del anima quodam modo omnia. Lo propio del intelecto es su «transparencia», en palabras de Polo, «la luz intrínsecamente atravesada de luz» ${ }^{93}$. Canals, precisa, el entendimiento «actúa por su íntima luminosidad, transparente a las formas de lo otro» ${ }^{94}$. Está transparencia es participación del acto.

87 Canals, F., «Sobre el punto de partida y el fundamento de la metafísica», p. 144.

88 Canals, F., «Sobre el punto de partida y el fundamento de la metafísica», p. 144.

89 «La intimidad de la reflexión por la que cada uno de los entes intelectuales creados se percibe a sí mismo como existente, le constituye en luminoso e iluminador "sub rationes entis» de cuanto existe en su conciencia como apto para ser manifestado y declarado»; CANALS, F., «El "lumen intellectus agentis" en la ontología del conocimiento de santo Tomás», p. 31.

90 Tomás de Aquino, De veritate, q, 8, a. 8, ad 3. La cursiva es mía.

91 Polo, L., Curso de teoría de conocimiento, III, p. 9. «El «esse» es tracendentalmente constitutivo de la inteligibilidad de lo que se ofrece como objeto»; CanaLs, F., "Sobre el punto de partida y el fundamento de la metafísica», p 160.

92 Polo, L., Antrolología trascendental. Tomo I: La persona humana (3ª ed.), Eunsa, Pamplona, 2010 p. 15.

93 Polo, L., Antrolología trascendental. Tomo I: La persona humana, p. 15.

94 Canals, F., «Sobre el punto de partida y el fundamento de la metafísica», p. 144. 
Si ascendemos en el orden del ser, llegamos al Primer principio: «identidad y subsistencia en sí del esse infinito y subsistente, identificado formalmente con la intelección subsistente de sí misma $»^{95}$. El primer analogado en la línea de la inteligibilidad es acto subsistente de entender ${ }^{96}$; por lo mismo, el conocer en Dios supera cualquier contenido especificativo ${ }^{97}$. Tal como ha señalado Canals, «al acto como tal no podría competirle el ser conocido según el modo y la relación de un mostrarse objetivo a un sujeto cognoscente» ${ }^{98}$. Dios, Primer analogado en el orden de la inteligibilidad, es «conciencia infinita, plenamente íntima» $»^{99}$, «esplendor» ${ }^{100}$.

Una forma separada, siendo formalmente luminosa, siempre será autopresencia de una determinada razón específica, no puro y subsistente esse. Ahora bien, el conocimiento que tiene de sí una forma separada tampoco consiste en «el modo y la relación de un mostrarse objetivo a un sujeto cognoscente». A una forma subsistente le compete conocerse según el modo de la subsistencia en sí del espíritu. En efecto, la subsistencia inmaterial consiste precisamente en que «la subsistencia intelectual y la inteligibilidad "intima" se identifican formalmente»" ${ }^{101}$. Como precisa Canals, la inteligibilidad antes de ser objetividad es presencia: manifestación del espíritu para sí según el ser que tiene en el individuo ${ }^{102}$.

95 Canals, F., «Sobre el punto de partida y el fundamento de la metafísica», p. 160.

96 Cfr. Canals, F., Sobre la esencia del conocimiento, pp. 492-493.

97 Cfr. Canals, F., «El "lumen intellectus agentis" en la ontología del conocimiento de santo Tomás», p. 117.

98 Canals, F., «Sobre el punto de partida y el fundamento de la metafísica», p. 160.

99 CANals, F., "El "lumen intellectus agentis" en la ontología del conocimiento de santo Tomás», p. 28. La cursiva es mía. Esta doctrina es nuclear en la obra del pensador catalán: «el acto puro de inteligibilidad, formalmente idéntico con el acto puro de intelectualidad, o entender subsistente, no es ya, en la cima del ascenso analógico, concebible como una perfecta aprehensión de un objeto existente en un inteligente en acto, sino como la infinita y plena conciencia del espíritu infinito, constituida por el acto subsistente de ser»; Sobre la esencia del conocimiento, pp. 498-499. «El arquetipo de todo conocimiento, la intuición infinita y originaria que se ha respecto al ente universal como el acto de todo ente se define por la posesión consciente de sí mismo formalmente idéntica con la subsitencia en sí plenamente íntima y actual del Ser simple e infinito»; "Sobre el punto de partida y el fundamento de la metafísica», p. 141. Maréchal ha subrayado esta misma cuestión: «El pensamiento de santo Tomás es otro. Muy lejos de oponer radicalmente sujeto y objeto en el conocimiento en general, proclama, por el contrario, la identidad total del sujeto y del objeto en la intuición perfecta de sí, tipo eminente de todo conocimiento. Una inteligencia tiene tanto menos necesidad de un inteligible distinto de ella cuanto es, si puede decirse así, más completamente inteligencia, más completamente en acto por la determinación subjetiva de su naturaleza misma. (...) En Dios (eliminada toda contingencia y realizando el Sujeto mismo la necesidad absoluta, que constituye también el ideal del Objeto, Inteligente e Inteligible, se confunden en la indivisión luminosa del Acto puro: la Intelección subsistente es a sí mismo su objeto primario"; MARÉCHAL, J., El punto de partida de la metafísica. Lecciones sobre el desarrollo histórico y teórico del problema del conocimiento (V), Gredos, Madrid, 1959, pp. 99-100.

100 Tomás de Aquino, Super Ioannem, c. 1 lect. 3.

101 Canals, F., «Verdad trascendental y subsistencia espiritual en Santo Tomás», p. 193.

102 Cfr. Canals, F., «Verdad trascendental y subsistencia espiritual en Santo Tomás», p. 193. 
Desde estas consideraciones, un inteligible en potencia puede ser caracterizado como aquella realidad que queda al margen de la presencialidad espiritual. El ente corpóreos no puede hacerse presente con su ser natural en la intimidad del cognoscente. Como acertadamente señala Canals, la inteligibilidad de un ente corpóreo es "objetiva" y extrapuesta al espíritu "consciente de sí” ${ }^{103}$. Entre el orden de lo inteligible y el universo de lo corpóreo se sitúa el alma humana. Ésta, si bien subsiste inmaterialmente, subsiste imperfectamente; de aquí que la luz connaturalmente poseída por ella no sea cognoscible sino en cuanto es acto de los inteligibles que han sido iluminados de las imágenes ${ }^{104}$.

\section{CARÁcter no obJetivable de La LUZ}

Avanzando más allá de lo hasta ahora señalado, se puede vincular el que el alma ocupe el último lugar en la escala de los entes inteligibles, con el hecho de que su luz no sea directamente cognoscible para el hombre ${ }^{105}$. Es doctrina asumida que en el pensamiento del Aquinate la luz inteligible no es objeto de un conocimiento explícito y temático ${ }^{106}$; esto es, en cuanto que trasciende toda determinación, la luz no es objetivable ${ }^{107}$. En efecto, lo objetivable es la especie inteligible que ha sido abstraída de las imágenes por la luz del entendimiento agente; de aquí la intrínseca ordenación de ésta a los fantasmas ${ }^{108}$. Santo Tomás precisa que la relación guardada entre el entendimiento y las imágenes es análoga a la que se da entre la luz del sol y los colores: «en nosotros no basta la luz del intelecto agente para tener un conocimiento distinto de las cosas, si no hay especies recibidas que sean informes por él; como la luz se comporta con los colores» ${ }^{109}$. Si los colores no estuviesen presente, la luz no podría determinar la vista.

Ahora bien, si la luz del agente no es objeto cognoscitivo es, no obstante, medio de conocer ${ }^{110}:$ :la luz del intelecto es quasi medium sub quo el entendimiento entiende ${ }^{111}$. En la línea de lo afirmado hasta ahora, el Aquinate señala

103 CAnALS, F., «Verdad trascendental y subsistencia espiritual en Santo Tomás», p. 193.

104 Cfr. Canals, F., «Sobre el punto de partida y el fundamento de la metafísica», p. 160

105 Cfr. Tomás de Aquino, Summa Theologiae, I, q. 88, a. 3, ad1; q. 79, a. 3, ad 1.

106 Cfr. Murillo, J. I., Operación, hábito y reflexión, p. 185.

107 «El entendimiento agente no puede objetivarse a sí mismo, no puede conocerse. Y esto es así porque es principio activo, principio objetivador y no objetivado»; GARCÍA CUADRADo, J. A., La luz del intelecto agente. Estudio desde la metafísica de Báñez, Eunsa, Pamplona, 1998, p. 179.

108 Cfr. Tomás de Aouino, De veritate, q. 19, a. 1.

109 Tomás de Aquino, In II Sententiarum, d, 3. q. 3, a. 4, ad 4. «Nam intellectus agens non est talis actus in quo omnium rerum species determinatae accipi possint ad cognoscendum; sicut nec lumen determinare potest visum ad species determinatas colorum, nisi adsint colores determinantes visum»; TomÁs DE Aquino, De anima, a. 5 ad 6.

110 Cfr. Tomás de Aouino, Summa Theologiae, I, q. 88, a. 3, ad 1.

111 Tomás de Aquino, De veritate, q. 18, a. 1, ad 1. Cfr. Quolibet, VII, q. 1, a. 1; In IV Sent, d. 49 , q. 2 , a. 1 , ad 15 . 
que el entendimiento agente es "principio activo del conocimiento» ${ }^{112}$, aquello "que hace que algo sea cognoscible»"113, «lo que pone en acto los objetos»" ${ }^{114}$, «el acto de las especies inteligibles» ${ }^{115}$. En razón de este su ser «medio de conocimiento", no siendo directamente lo conocido, la luz comparece en todo conocer. Tal como sugiere Canals, «si el acto no es en sí mismo objetivo es por cierto objetivante» ${ }^{116}$. Santo Tomas sostiene que «la luz del intelecto agente es entendida por nosotros por sí misma, en cuanto es la razón de las especies inteligibles, haciendo que ellas sean inteligibles en acto" ${ }^{117}$. La luz inteligible es conocida en todo acto de conocer ${ }^{118}$. Determinar qué «tipo» de conocimiento es éste, es lo que nos proponemos dilucidar.

El camino escogido para plantear esta cuestión ha sido el de estudiarla en relación al conocimiento que tiene cada alma en cuanto que posee el ser por sí, secundum quod habet esse in tali individuo. La razón de esta elección ha sido el constatar que ambos conocimientos tienen como notas distintivas el tratarse de un «saber» indirecto e inobjetivo. El lugar en el que santo Tomás desarrolla exhaustivamente esta cuestión es el artículo 10 de la questión 8 del De Veritate. En él santo Tomás distingue un doble conocimiento que el alma tiene de sí: un conocimiento esencial, y otro existencial ${ }^{119}$. Ambos conocimiento se distinguen

112 Tomás de Aquino, De veritate, q. 8, a. 8, ad 3.

113 Tomás de Aquino, In De Trinitate, pars 1, q. 1, a. 3, ad 1.

114 Tomás de Aouino, Summa Theologiae, I, q. 79, a. 4, ad 3.

115 Tomás de Aquino, Summa Theologiae, I, q. 87, a. 1.

116 CanAls, F., «Sobre el punto de partida y el fundamento de la metafísica», p. 160. El entendimiento agente es «ciertamente inteligible en sí, pero no lo es inmediatamente para sí. No es, efectivamente, objeto de conocimiento ni puede serlo jamás, puesto que "constituye al objeto en acto". Siendo objetivador, no puede ser objetivado»; MARC, A., Psicología reflexiva (I), El conocimiento. Gredos, Madrid, 1965. p. 1965.

117 Tomás de Aquino, De veritate, q. 10, a. 8 ad sc 10. La cursiva en mía.

118 «Nec tamen oportet quod etiam ipsum lumen inditum sit primo a nobis cognitum. Non enim eo alia cognoscimus sicut cognoscibili quod sit medium cognitionis, sed sicut eo quod facit alia esse cognoscibilia. Unde non oportet quod cognoscatur nisi in ipsis cognoscibilibus, sicut lux non oportet quod primo videatur ab oculo nisi in ipso colore illustrato»; ToмÁs DE Aquino, In De Trinitate, pars 1, q. 1, a. 3, ad 1. Las cursivas son mías. "Alio tamen modo, secundum philosophos, intelligitur quod anima semper se intelligit, eo quod omne quod intelligitur, non intelligitur nisi illustratum lumine intellectus agentis, et receptum in intellectu possibili. Unde sicut in omni colore videtur lumen corporale, ita in omni intelligibili videtur lumen intellectus agentis; non tamen in ratione objecti sed in ratione medii cognoscendi»; Tomís de Aouino, In I Sententiarum, d. 3, q. 4, a. 5. La cursiva es mía. Cory afirma: "Consequently, Thomas seems to be arguing that the intellect always perceives its own light as part of its perception of any known object-not distinctly, as though the intellect were discerning or cogitating the nature of its own light, nor attentively, as an object in its own right, but rather as a fundamental yet unnoticed element within the perception»; Thomas Aquinas and the Problem of Human Self-Knowledge, PhD diss., Catholic University of America, 2009, p. 52.

119 Se debe destacar sobre esta cuestión el trabajo de GARDEIL, A., La structure de l'âme et l'expérience mystique II, J. Gablada, París, 1927. El conocimiento existencial que el alma tiene de sí, por otra parte, ha sido exhaustivamente estudiado por la denominada Escuela Tomista de Barcelona. Recientemente el interés por esta temática ha sido revitalizado. Dentro 
por aquello de lo que dan noticias. Mientras que el primero da a conocer cuál sea la esencia del alma, el existencial otorga una percepción del propio esse. Dada la naturaleza diversa de uno y otro, el proceder por el cual se alcanza cada uno es disímil. Mientras que para conocer la esencia del alma se requiere realizar una sutil investigación, el conocimiento de la propia existencia es inmediato ${ }^{120}$. Ahora bien, que sea inmediato, no lleva consigo que el hombre esté siempre en acto sabiéndose ser.

Santo Tomás distingue un conocimiento existencia habitual y otro actual. Para el conocimiento existencial habitual vasta la sola presencia del alma. En efecto, «el alma se ve a sí misma mediante su propia esencia» 121 . Luego, «(..) para que el alma perciba que existe y se percate de lo que se actúa en ella, no se requiere hábito alguno, sino que a ello es suficiente la sola esencia del alma que está presente a la mente; de ella, en efecto emanan los actos en los que ella misma se percibe actualmente» ${ }^{122}$. Puesto que su esencia le es presente, el alma «es capaz de pasar al acto del conocimiento de sí misma» ${ }^{123}$ por sí misma; esto es, con solo realizar una operación inmanente ${ }^{124}$. Al percatarse de que obra, el alma percibe que es ${ }^{125}$. En este sentido, santo Tomás precisa que el alma se conoce por sus actos ${ }^{126}$, el ángel, en cambio, se conoce por su esencia.

El conocimiento de la propia existencia es un conocer perceptivo, experimental, no expresable por medio de discurso; un conocimiento presencial y

del mundo académico hay tres trabajos que se han de considerar, Le sens de la réflexion chez Thomas d'Aquin de François-Xavier Putallaz (1991), Self Knowledge in Thomas Aquinas: The Angelic Doctor on the Soul's Knowledge of Itself de Richard Lambert (2007) y Aquinas on Human Self-Knowledge de T. S. Cory (2014).

120 En la tradición anglosajona se a optado por denominar al primero de estos conocimientos «self-awareness» y al segundo "self-knowledge». Cfr. B. Goehering, "St. Thomas Aquinas on Self-Knowldedge and Self Awareness», Cithara 2003 (42), p. 4. T. S. Cory, Thomas Aquinas and the Problem of Human Self-Knowledge, p. 57.

121 Tomás de Aouino, De veritate, q. 10, a .8.

122 Tomás de Aquino, De veritate, q. 10, a. 8. "Nam ad primam cognitionem de mente habendam, sufficit ipsa mentis praesentia, quae est principium actus ex quo mens percipit seipsam Et ideo dicitur se cognoscere per suam praesentiam. Sed ad secundam cognitionem de mente habendam, non sufficit eius praesentia, sed requiritur diligens et subtilis inquisitio»; Tomás de Aouino, Summa Theologiae, I, q. 87, a. 1. A diferencia de otros hábitos, el conocimiento existencial habitual que el alma tiene de sí, no se refiere a conceptos, no está en la línea de la esencia. Sin embargo, tiene de común con otros hábitos cognoscitivos, que el cognoscente lo puede actualizar de sí mismo; Cfr. E. Forment. «Estudio preliminar» en El ente y la esencia, ( ${ }^{\mathrm{a}}$ ed.), Eunsa, Pamplona, p. 114; J. García López, «El conocimiento del yo según santo Tomás», Anuario Filosófico, 1971 (4), p. 103.

123 Tomás de Aquino, De veritate, q. 10 , a .8 .

124 Cfr. Tomás de Aouino, De veritate, q. 10, a. 8; q. 87, a. 1.

125 Cfr. Tomás de Aquino, Contra Gentes, III, 46.

126 Cfr. Tomás de Aouino, De veritate, q. 10, a. 8. «In hoc enim aliquis percipit se animam habere, et vivere, et esse, quod percipit se sentire et intelligere, et alia huiusmodi vitae opera exercere; unde dicit philosophus in IX Ethicorum: sentimus autem quoniam sentimus; et intelligimus quoniam intelligimus; et quia hoc sentimus, intelligimus quoniam sumus»; Томás De Aouino, De veritate, q. 10, a. 8. 
no abstractivo ${ }^{127}$. Es un saber que puede ser caracterizado como una percepción: "cada uno experimenta en sí mismo que tiene alma y que los actos del alma están en él» ${ }^{128}$. Bofill sintetiza las notas distintivas de este conocimiento afirmando que es un conocimiento actual, oponiéndo este término a objetivo «nocional» ${ }^{129}$. En efecto, siendo verdadero conocimiento, el conocimiento existencial del alma no es objetivo, i.e. universalmente enunciable. Canals, Forment y Murillo, subrayan esta cuestión: puesto que es contingente, este conocimiento no otorga una evidencia objetiva. Esto es, su negación no resulta incompatible con el principio de no contradicción ${ }^{130}$. Tal ausencia de objetividad, sin embargo, no afecta a la evidencia simpliciter de este juicio ${ }^{131}$. Por último, se ha de señalar que el conocimiento existencial posee un carácter intransferible, «tal que cualquier otro hombre puede ciertamente "creerle" si de él habla, pero que sólo él posee por sí mismo» ${ }^{132}$.

Existe un claro paralelo entre el conocimiento existencial del alma y el conocimiento de la luz inteligible que acompaña a toda intelección objetiva. El primero, no obstante, es más amplio que el segundo: el alma se sabe existente al realizar cualquier operación inmanente. La relación entre uno y otro es explícitamente sugerida por santo Tomás: «según los filósofos, que el alma siempre se entiende a sí misma se interpreta también de otro modo, puesto que todo lo que se entiende, solamente es entendido en cuanto que iluminado por la luz del entendimiento agente y en cuanto es recibido en el entendimiento paciente. Por lo tanto, de la misma manera que en cada uno de los colores se ve la luz corporal, así también en todo inteligible se ve la luz del entendimiento agente; pero no bajo el aspecto de objeto, sino bajo el aspecto de medio cognoscitivo ${ }^{133}$.

Al comentar a san Agustín, el Aquinate precisa que «el conocimiento por el que el alma se conoce a sí misma no pertenece al género de los accidentes en cuanto a aquello por lo que es conocida habitualmente, sino sólo en cuanto al acto de conocimiento, el cual es un cierto accidente; por eso también san Agustín dice, en el libro IX de Sobre la Trinidad, que el conocimiento está presente a la mente de modo sustancial, por cuanto la mente se conoce a sí misma» ${ }^{134}$. Si en el hombre el acto de conocimiento humano está directamente dirigido a lo diverso de sí, es puesto que el alma humana es forma de un cuerpo. Ahora bien, en cuanto que poseedora del ser por sí, el alma humana es autopresente. Esta autopresencialidad es el modo humano de participación proporcional

127 Cfr. Canals, F., Sobre la esencia del conocimiento, p. 96.

128 Tomás de Aquino, De veritate, q. 10, a. 8 , ad sc 8.

129 Cfr. Bofill, J., «Para una metafísica del sentimiento», p. 118.

130 Cfr. Canals, F., Sobre la esencia del conocimiento, pp. 99-100. Cfr. J. I. Murillo, Operación, hábito y reflexión, p. 186; Forment, E., Introducción a la metafísica, Edicions Universitat de Barcelona, Barcelona, 1984, pp. 42-43. Santo Tomás afirma esta cuestión explícitamente en De veritate, q. 10, a 12, ad 7.

131 Cfr. Forment, E., Introducción a la metafísica, p. 43.

132 Canals, F., Sobre la esencia del conocimiento, p. 96.

133 Tomás de Aouino, In I Sententiarum, d. 3, q. 4, a. 5. La cursiva en mía.

134 Tomás de Aquino, De veritate, q. 10, a. 8 ad 14. La cursiva es mía. 
en la conciencia infinita y plenamente íntima que es Dios ${ }^{135}$. En efecto, como subraya Canals, la memoria que la mente tiene de sí, «es constitutiva y radicalmente desbordante de su propia entidad y por sí misma destinada a dar a la mente, como "memoria de sí misma para sí misma", aquella dimensión infinita por la que la memoria posee en sí la inmensidad y diversidad del universo conocido» ${ }^{136}$.

Universidad San Dámaso (Madrid)

Rosario NeUman

rosameuman@yahoo.es

[Artículo aprobado para publicación en diciembre de 2014]

135 «Por este mínimo grado de participación del Acto puro que es "Esse” e "intelección” subsistente, esta "reflexión" o "noticia habitual" del alma se actuará en la iluminación que hace de los inteligibles en acto, por los que el hombre entiende»; CANALS, F., "El "lumen intellectus agentis" en la ontología del conocimiento de santo Tomás», p. 38.

136 Canals, F., Sobre la esencia del conocimiento, p. 300. «Las cosas están ónticamente inscritas en el ser del hombre antes de estarlo conscientemente, pues está constitutivamente abierto a ellas». Bofill, J., "Concepto y método de la metafísica», en Obra filosófica, Ariel, Barcelona, 1967, p. 31. "La misma presencia connatural de la luz, da, pues, a la mente su dinamismo infinitamente asimilador que la inclina a la "descripción en sí de todo el orden del Universo y sus causas"». CANALS, F., «El "lumen intellectus agentis" en la ontología del conocimiento de santo Tomás», p. 38. 